\title{
Estado punitivo brasileiro \\ A indeterminação entre democracia e autoritarismo
}

\author{
Brazilian punitive state \\ Indeterminacy between democracy and authoritarianism
}

Débora Regina Pastana*

\begin{abstract}
Resumo: O tema central deste artigo é o crescente investimento no combate ao crime pelos atuais governos democráticos brasileiros, o que contribui para consolidar, também entre nós, a figura do "estado punitivo". O atual arranjo capitalista generaliza-se quase que instantaneamente em todo o globo, atrelando o sucesso dos empreendimentos econômicos à nova face da política criminal. Nesse sentido, o estado punitivo passa a caracterizar uma ambiguidade que simbolicamente é o retrato do momento político contemporâneo. Dito de outra forma, em torno desse modelo de controle misturam-se conceitos absolutamente contraditórios como democracia e autoritarismo. Inserido nas recentes reflexões sociológicas de Loïc Wacquant, David Garland, Nils Christie, Zygmunt Bauman e Giorgio Agamben, entre outros, esse tema começa a ser discutido também pela comunidade acadêmica nacional. $\mathrm{O}$ artigo, portanto, tem como objetivo abordar o que se convencionou chamar de "estado punitivo", figura política que se ajusta às transformações econômicas, sociais e culturais já em curso nos últimos trinta anos e que desponta no Brasil como forma cada vez mais hegemônica de controle social.
\end{abstract}

Palavras-chave: Estado punitivo. Democracia. Autoritarismo.

Abstract: The central theme of this article is the growing investment in combating crime by the current democratic governments in Brazil, which contributes to consolidate also among us, the figure of "punitive state." The current capitalist arrangement generalizes almost instantaneously across the globe, tying the success of the new economic businesses considering criminal policy. Accordingly, the punitive state characterizes

\footnotetext{
* Doutora em Sociologia pela Universidade Estadual Paulista (Unesp), é professora do Instituto de Ciências Sociais e membro do corpo docente permanente dos PPGs em Ciências Sociais e de Direito Público da Universidade Federal de Uberlândia (UFU), em Uberlândia, MG, Brasil, e coordena o grupo de estudos sobre violência e controle social (Gevico) $<$ http://www.gevico. sociais.ufu.br/>. A pesquisa contou com apoio da Pró-Reitoria de Pesquisa e Pós-Graduação da UFU < deborarepastana@bol.com.br>.
}

\begin{tabular}{|l|l|l|l|l|l|}
\hline Civitas & Porto Alegre & v. 13 & n. 1 & p. $27-47$ & jan.-abr. 2013 \\
\hline
\end{tabular}


an ambiguity that is symbolically the portrait of the contemporary political moment. Put another way, around this control, thoroughly contradictory concepts are mixed as democracy and authoritarianism. Present in recent sociological reflections of Loïc Wacquant, David Garland, Nils Christie, Zygmunt Bauman and Giorgio Agamben, among others, this theme also begins to be discussed by the national academic community. The paper therefore aims to address what has been called "punitive state," political figure who portrays the economic, social and cultural changes already underway in the last thirty years and that rises in Brazil as an increasingly hegemonic control. Keywords: Punitive state. Democracy. Authoritarianism.

\section{Introdução}

O tema central deste capítulo é o crescente investimento no combate ao crime pelos recentes governos democráticos brasileiros. Sob esse prisma se materializa a figura do estado punitivo que, nas palavras de Wacquant (2001), caracteriza-se por diminuir suas prerrogativas na frente econômica e social e por aumentar suas missões em matéria de segurança, "subitamente relegada à mera dimensão criminal". Nesse sentido ficam cada vez mais evidentes as posturas autoritárias que, atreladas ao liberalismo contemporâneo, vêm sendo incorporadas pelo estado brasileiro.

Nas três últimas décadas as pesquisas em torno da criminalidade e da segurança pública assumiram uma importância significativa perante as universidades brasileiras. Essa importância se traduz na criação de inúmeros centros de estudos direcionados como, por exemplo, o Núcleo de Estudos da Violência (NEV) vinculado à Pró-Reitoria de Pesquisa da Universidade de São Paulo (USP) e o Centro de Estudos de Criminalidade e Segurança Pública (Crisp) da Universidade Federal de Minas Gerais (UFMG).

As linhas de pesquisa desses centros buscam compreender as causas da criminalidade, além de realizarem projetos interdisciplinares visando o aprimoramento da segurança pública no país. Alguns elaboram "mapeamento de crimes" para auxiliar o planejamento e o gerenciamento das atividades policiais; outros desenvolvem, em parceria com o poder público, estratégias e programas de controle em nível local. Há também o oferecimento de cursos voltados para a capacitação de pessoas envolvidas com segurança e o desenvolvimento de projetos para a melhoria na gestão penitenciária. Em todos é possível verificar uma preocupação comum, vale dizer, a efetivação dos direitos humanos como caminho para a consolidação democrática nacional. Suas análises são variadas, contribuindo sobremaneira para a compreensão da criminalidade violenta no Brasil e para a ampliação do debate nacional sobre a gestão pública do controle. 
Contudo, apesar da relativa abundância de pesquisas retratando violência e seus temas correlatos, ainda não se destaca no Brasil, como objeto específico de reflexão, o real significado das atuais posturas políticas relacionadas ao controle penal. Os trabalhos relativos à segurança pública produzidos atualmente, em sua maioria, preocupam-se ainda em discutir a eficácia, ou na maioria das vezes, a ineficácia, das instituições de controle. Ignoram muitas vezes que "a resposta tecnocrática ao problema da criminalidade concentra-se nos efeitos do delito (uma imagem projetada e politizada da vítima, o medo, os custos com a segurança), mais do que nas raízes estruturais (econômicas e sociais) e político-ideológicas da questão" (Argëllo, 2005, p. 2). De fato, não se vislumbra por parte do estado brasileiro preocupação significativa com a origem estrutural (desigualdade social e abandono do poder público) dos vários tipos de violência que atemorizam a sociedade atual. Ao contrário, os recentes governos têm optado em responder a tais conflitos sociais com justificativas meramente retóricas que, apoiadas por uma opinião pública viciada, apontam para a perversa demonização de um inimigo interno personificado na figura do criminoso, elemento este selecionado entre os membros mais miseráveis das classes populares.

De acordo com Wacquant (2007, p. 126-127) esse modelo neoliberal de gestão penal destina-se a "regular, senão perpetuar, a pobreza e armazenar os dejetos humanos do mercado".

Volta-se para aqueles que compõem o subproletariado negro das grandes cidades, as frações desqualificadas da classe operária, aos que recusam o trabalho mal remunerado e se voltam para a economia informal da rua, cujo carro-chefe é o tráfico de drogas (Wacquant, 1999, s. p.).

Com efeito, essa penalidade neoliberal, denominada por Wacquant (2001, p. 10) de "ditadura sobre os pobres" procura reprimir com severidade "as desordens suscitadas pela desregulamentação da economia, pela dessocialização do trabalho assalariado e pela pauperização relativa e absoluta de amplos contingentes do proletariado urbano, aumentando os meios, a amplitude e a intensidade da intervenção do aparelho policial e judiciário".

Assim, mostra-se oportuno, nesse momento obsessivo por segurança, questionar o que há de simbólico nas políticas penais atuais, para em grande medida associá-las ao projeto liberal em curso no país. Aqui partimos do pressuposto essencial de que a atual expansão do controle penal não pode ser analisada sem considerarmos sua direta ligação ao recente projeto liberal implementado em praticamente todo o Ocidente capitalista. Mesmo 
países que não adotaram o anterior modelo de estado de bem-estar, como o Brasil, paulatinamente começaram a abandonar políticas penais de natureza preventivas e passaram a adotar modelos meramente punitivos e repressores. $\mathrm{O}$ objetivo deste artigo, portanto, é oferecer um enfoque alternativo às reflexões sobre o controle penal, apontando os paradoxos presentes na atuação do estado brasileiro relacionados ao tema e sua responsabilidade diante dos impasses na consolidação democrática nacional.

\section{Nova ordem penal}

Nos últimos trinta anos transformações significativas que afetaram o perfil da economia mundial começaram a despontar, acarretando também mudanças na configuração política dos estados e nas formas de sociabilidade. A simbólica derrubada do muro de Berlim e as reformas políticas soviéticas que culminaram no fim da URSS representaram a magnitude das mudanças e o rumo político que elas provocaram. Na mesma direção, o Consenso de Washington e suas regras universais passaram a dominar o cenário político ocidental tornando-se o espectro econômico de quase todas as nações. Reestruturação produtiva, liberação dos mercados, privatização de indústrias e serviços, desregulamentação das relações de trabalho, flexibilização salarial, desemprego estrutural e redução das políticas públicas de inclusão social são apenas algumas das características desse limiar neoliberal. $\mathrm{O}$ fato é que o mundo está cada vez mais diligente com a economia e menos preocupado com o social. Na esfera da criminalidade e dos mecanismos de controle relacionados ao desvio, o período também foi marcado por uma série de alterações consideradas retrocessos políticos para muitos estudiosos do tema.

Os recentes desdobramentos em matéria de controle do crime e da justiça criminal são intrigantes porque envolvem uma súbita e perturbadora subversão do padrão histórico assentado. Mostram uma aguda descontinuidade que reclama explicação. Os processos modernizantes que, há tão pouco tempo, pareciam sedimentados neste domínio - acima de todas as tendências de longo prazo que apontavam para a "racionalização" e para a "civilização" - agora aparentam ter engatado a marcha à ré”. A reaparição, na política oficial, de sentimentos punitivos e de gestos expressivos, que parecem estranhamente arcaicos e absolutamente antimodernos, tende a confundir as teorias sociais comuns sobre a punição e seu desenvolvimento histórico. Nem mesmo o mais criativo leitor de Foucault, Marx, Durkheim e Elias poderia prever estes desdobramentos recentes, e certamente nenhuma previsão deste tipo jamais surgiu (Garland, 2008, p. 44). 
De fato, destaca-se no contexto político atual uma forte preocupação com a gestão da segurança pública. É cada vez mais evidente a atenção estatal com o controle penal. Assim, compreender essa nova configuração política, mais combativa frente aos conflitos sociais, e pouco preocupada em questionar a origem dos mesmos, é de fundamental importância para as Ciências Sociais, na medida em que permite desvendar as atuais tendências autoritárias hegemonicamente articuladas em praticamente todo o Ocidente. É justamente esse tipo de observação que aqui determina um outro enfoque nas reflexões sobre o controle social. Para autores como Wacquant (2007), Garland (2008), Christie (2002) e Bauman (1999), por exemplo, o atual arranjo capitalista generaliza-se quase que instantaneamente em todo o globo, atrelando o sucesso dos empreendimentos econômicos à nova face da política criminal. Tal associação política é cada vez mais emblemática nas sociedades democráticas contemporâneas, refletindo um novo paradigma de controle social traduzido não apenas em um exercício autoritário, mas, acima de tudo, numa atuação antidemocrática hegemonicamente reconhecida como necessária.

A presente era de globalização do capitalismo, que arrasta consigo a globalização dos conflitos e dos riscos, é marcada, sob o domínio legitimador da ideologia neoliberal, por um duplo movimento, a saber, de maximização do poder econômico globalizado x minimização do poder político nacional e fragilização dos canais tradicionais de mediação política entre estado e comunidade, ou seja, dos atores políticos tradicionais (partidos, parlamento, administração) e do espaço público democrático. No prolongamento deste movimento e como seu retrato intrassistêmico desenvolve-se um outro, de reengenharia institucional: o de maximização do estado penal $\mathrm{x}$ minimização do estado social (a que vimos denominando estado do mal-estar penal). Ao estado neoliberal mínimo no campo social e da cidadania, passa a corresponder um estado máximo, onipresente e espetacular, no campo penal. [...] Os déficits de dívida social e cidadania são ampla e verticalmente compensados com excessos de criminalização; os déficits de terra, moradias, educação, estradas, ruas, empregos, escolas, creches e hospitais, com a multiplicação de prisões [...]. Estamos perante autêntica "indústria do controle do crime" (Christie, 1998) que, realizando a passagem do "estadoprovidência" ao "estado-penitência" (Wacquant, 2001), cimenta as bases de um "genocídio em marcha", de um "genocídio em ato" (Zaffaroni, 1991) (Andrade, 2009, p. 42).

Esse momento que vivenciamos começa a ganhar distintas denominações e diagnósticos que, embora complexos e com variações consideráveis, começam a caracterizar os estados como autoritários e violentos. Nesse sentido, se é 
certo que "a emergência da pós-modernidade ${ }^{1}$ está estritamente relacionada à emergência desta nova fase do capitalismo avançado, multinacional e de consumo" (Jameson, 1985, p. 10), em matéria penal ela se evidencia por meio do endurecimento generalizado das políticas penais e penitenciárias. ${ }^{2}$

Recentemente parte considerável da humanidade se vê inserida na tendência homogênea de obsessão securitária. De acordo com Wacquant "a inconteste hegemonia do pensamento neoliberal sobre segurança dos dois lados do Atlântico" associou a "'mão invisível' do mercado do trabalho desqualificado com o seu prolongamento ideológico e seu complemento institucional no 'punho de ferro' do estado penal" (Wacquant, 2007, p. 40). Ainda segundo Wacquant, (2001, p. 7), a "penalidade neoliberal apresenta o seguinte paradoxo: pretende remediar com um 'mais estado' policial e penitenciário o 'menos estado' econômico e social que é a própria causa da escalada generalizada da insegurança objetiva e subjetiva em todos os países".

É, de fato, possível argumentar que atualmente "a atrofia planejada do estado social [...] e a súbita hipertrofia do estado penal são dois movimentos concomitantes e complementares" (Wacquant, 2007, p. 40). O advento de uma economia marcada pelo abandono do compromisso keynesiano e pela acumulação flexível produziu o agravamento das desigualdades sociais e dos processos de exclusão social em escala global. Em contrapartida, os governos

\footnotetext{
Tema controverso na teoria social contemporânea, alguns pensadores começam a associar as atuais transformações provocadas pelo desenvolvimento capitalista a um novo momento histórico. O ressurgimento do liberalismo econômico e político e suas consequências imediatas, vale dizer, a reestruturação dos setores produtivos e a flexibilização das relações de trabalho apontam para um momento que Giddens (1995) chama de "modernidade tardia", Beck (1995) de "modernidade reflexiva", Bauman (2001) de "modernidade líquida" e Jameson (1985) e Harvey (2010), entre outros, de "pós-modernidade". Sem entrar no mérito desse tema tão combativo, podemos simplesmente afirmar que o tempo que vivemos é, em grande parte do mundo, marcado pela diminuição de políticas sociais e pelo aumento de políticas penais.

2 Por certo que no Brasil, assim como na maioria dos países da América Latina, essa constatação antecede a recente ascensão do modelo econômico liberal. De fato, nossa arbitrariedade relacionada ao controle social está atrelada a questões mais complexas da nossa história política. Neder (1996) chega afirmar que em nossa formação socioeconômica desenvolvemos fantasias de controle social absoluto a partir da cultura jurídico-política da Península Ibérica. Batista (2001, p. 26), ao comentar tal afirmação, destaca que "nem o fim da escravidão nem a República romperam com o legado da fantasia absolutista do controle social [...] A atuação da polícia nas favelas cariocas, tanto quanto a chacina de Eldorado dos Carajás, é a prova viva deste legado". O próprio Wacquant (2001, p. 8), em nota que fez aos brasileiros no livro As prisões da miséria, chama atenção para as especificidades do Brasil. Segundo o autor, por um conjunto de razões ligadas a nossa história e nossa "posição subordinada na estrutura das relações econômicas internacionais (estrutura de dominação que mascara a categoria falsamente ecumênica de 'globalização')", e a despeito do enriquecimento coletivo das décadas de industrialização, nossa sociedade "continua caracterizada pelas disparidades sociais vertiginosas e pela pobreza de massa que, ao se combinarem, alimentam o crescimento inexorável da violência criminal, transformada em principal flagelo das grandes cidades".
} 
locais se apresentam como os principais responsáveis pelo controle das consequências desses processos.

No mundo das finanças globais, os governos detêm pouco mais que o papel de distritos policiais superdimensionados; a quantidade e qualidade dos policiais em serviço, varrendo os mendigos, perturbadores e ladrões das ruas, e a firmeza dos muros das prisões assomam entre os principais fatores de "confiança dos investidores" e, portanto, entre os dados principais considerados quando são tomadas decisões de investir ou de retirar um investimento. Fazer o melhor policial possível é a melhor coisa (talvez a única) que o estado possa fazer para atrair o capital nômade a investir no bem-estar dos seus súditos; e assim o caminho mais curto para a prosperidade econômica da nação e, supõe-se, para a sensação de "bem-estar" dos eleitores, é a da pública exibição de competência policial e destreza do estado (Bauman, 1999, p. 128).

Nesse contexto, a gestão da segurança pública é "concebida e executada não tanto por ela mesma, mas sim com a finalidade expressa de ser exibida e vista, examinada e espionada: a prioridade absoluta é fazer dela um espetáculo, no sentido próprio do termo" (Wacquant, 2007, p. 9).

Assim, a maior parte das medidas penais recentes, engajadas em um modo de ação que expressa a necessidade constante de punição severa, traduzindo o sentimento público de intranquilidade e insegurança e insistindo nos objetivos retributivos ou denunciadores, atestam, ao mesmo tempo, seu caráter inequivocamente "punitivo".

As medidas que configuram tal postura são pouco originais e singularmente violentas: condenações mais severas, encarceramento massivo, leis que estabelecem condenações obrigatórias mínimas e perpetuidade automática no terceiro crime ("three strikes and you're out"), estigmatização penal, restrições à liberdade condicional, leis que autorizam prisões de segurança máxima, reintrodução de castigos corporais, multiplicação de delitos aos quais são aplicáveis pena de morte, encarceramento de crianças (aplicação de legislação criminal "adulta" aos menores de 16 anos), políticas de "tolerância zero", etc. Enfim, são legislações que nada mais expressam do que o desejo de vingança orquestrado pelo velho discurso da "lei e da ordem" (Argëllo, 2005, p. 1).

Importante destacar que desse contexto recente emergem discursos científicos que procuram legitimar tal endurecimento penal como, por exemplo, as preleções de Jakobs (2003) sobre um Direito Penal do Inimigo. Segundo o autor os inimigos contemporâneos seriam tanto os terroristas 
quanto os criminosos econômicos, os delinquentes organizados, os autores de delitos sexuais e outros infratores penais perigosos (Jakobs, 2003, p. 39). Em outras palavras, é inimigo quem se desvia permanentemente do Direito recusando-se a retornar ao fiel cumprimento da norma. Ainda segundo o autor, os inimigos atuais não devem ser tratados como cidadãos, não sendo sujeitos processuais. "Cabe ao estado não reconhecer seus direitos, ainda que de modo juridicamente ordenado" (Jakobs, 2003, p. 45). Contra o inimigo não há devido processo legal, ao contrário, declara-se guerra.

Não sem razão, portanto, que Oliveira (2000, p. 59-63) observa, já no começo do século, a existência de uma "exceção permanente", uma espécie de "antidemocracia na América", que se refugia no simulacro de constitucionalidade, e que, em suas palavras, "mal disfarça uma dominação que, outra vez, inverte a fórmula, gramsciana, de $80 \%$ de consenso e $20 \%$ de violência, para as proporções opostas". Em escala global, essa pode ser também a imagem do recorrente "estado de exceção" retratado por Agamben (2004, p. 13) ao apontá-lo como paradigma de governo dominante na política contemporânea. Ainda segundo o autor:

Esse deslocamento de uma medida provisória e excepcional para uma técnica de governo ameaça transformar radicalmente - e, de fato, já transformou de modo muito perceptível - a estrutura e o sentido da distinção tradicional entre os diversos tipos de constituição. $\mathrm{O}$ estado de exceção apresenta-se, nessa perspectiva, como um patamar de indeterminação entre democracia e absolutismo (Agamben, 2004, p. 13).

Enfim, é justamente essa democracia, pontuada por estados de emergência permanentes, que aqui é objeto de reflexão. Aderindo às observações de Agamben, esse artigo também reconhece que, sem alterar os ritos democráticos, o controle penal se expande de forma extraordinária e autoritária. Há mais de duas décadas vivemos sob a égide de uma Constituição democrática, no entanto, as relações entre os governos e a sociedade caracterizam-se cada vez mais pela ilegalidade e arbitrariedade.

\section{O estado brasileiro: três poderes e um só discurso de recrudescimento penal}

A partir de agora, o artigo pretende focalizar politicamente a análise do controle social brasileiro destacando características particularmente punitivas e que se alinham ao modelo de gestão contemporâneo marcado pelo recrudescimento penal. Tal pretensão se apoia no reconhecimento de que, 
atualmente, todos os poderes do estado brasileiro estão alinhados na mesma postura punitiva. Em outras palavras, observa-se no contexto político atual uma forte adesão do executivo, do legislativo e do judiciário, aliados às forças armadas, às premissas de endurecimento punitivo. Esse modelo de gestão ostensivo relacionado ao controle social alinhava todos os setores do estado em um único discurso e em uma ação coordenada que, de forma implacável, fragiliza significativamente o ambiente democrático.

Conforme destacado anteriormente, essa postura política parte de um modelo liberal estabelecido no final dos anos 1970 e se sobrepõe aos regimes democráticos, ainda que formalmente não contraste com os textos constitucionais. Por certo que os estados nacionais vêm sofrendo um processo de reconfiguração política adequada ao receituário neoliberal. No Brasil ${ }^{3}$ não foi diferente. Entre nós é também possível visualizar o que Garland (1999) chamou de "obsessão securitária" que direciona as políticas criminais para um maior rigor em relação às penas e maior intolerância para com o criminoso.

É bom salientar que não é de hoje ${ }^{4}$ que o estado brasileiro adota uma política penal de exceção, contrária às noções de democracia e cidadania, e que coloca "a questão social como um caso de polícia". O presidente Washington Luís pode ter eternizado a frase que resume essa postura autoritária, mas a política já existia antes dele e continua nos dias atuais, agora perfeitamente adaptada ao contexto neoliberal. Entre nós a consolidação do estado punitivo apenas agrava nossos males históricos, vale dizer, a "deslegitimação das instituições legais e judiciárias, a escalada dos abusos policiais, a criminalização dos pobres, o crescimento significativo da defesa das práticas ilegais de repressão, a obstrução generalizada ao princípio da legalidade e a distribuição desigual e não equitativa dos direitos do cidadão" (Wacquant, 2001, p. 12). Nesse contexto, o controle social brasileiro apresenta-se ainda mais autoritário e seletivo, traduzido em aumento desproporcional de penas, maior encarceramento, supressão de direitos e garantias, endurecimento da execução penal entre outras medidas igualmente severas.

\footnotetext{
3 Nosso legado de autoritarismo e pouca resistência cidadã facilitou, em grande medida, a adequação do projeto neoliberal no fim dos anos 1980. Como bem observa Loïc Wacquant (2001, p. 7) "a penalidade neoliberal ainda é mais sedutora e mais funesta quando aplicada em países ao mesmo tempo atingidos por fortes desigualdades de condições e de oportunidades de vida e desprovidos de tradição democrática e de instituições capazes de amortecer os choques causados pela mutação do trabalho e do indivíduo no limiar do novo século".

4 Fazendo referência a essa especificidade, Argëllo (2005, p. 1) atesta que "na América Latina, a preocupação com a violência criminal também se tornou uma obsessão coletiva e toma proporções que, de tão graves, lembram os tempos sombrios das ditaduras militares, quando a doutrina de segurança nacional legitimava a tortura e todas as demais formas de violação dos direitos humanos, em nome da razão de estado. Hoje, é no altar da ideologia da segurança pública que se tornam facilmente sacrificáveis a democracia e os direitos humanos".
} 
Neste início de milênio, quase todas as esferas da vida social, íntimas ou públicas, foram investidas e pensadas tendo como foco as questões de segurança. Ela está na ordem do dia em termos das preocupações de qualquer cidade, em qualquer quadrante do mundo. Mesmo em países como o Brasil, nos quais a pobreza e o desemprego assumem dimensões alarmantes, as pesquisas de opinião têm apontado a crescente preocupação das pessoas com a violência e com o crime. A segurança tem eclipsado outras mazelas sociais urgentes do país. Os resultados dessa obsessão securitária estão expressos claramente no aumento dos contingentes policiais, no crescimento da população carcerária, na maior sofisticação dos equipamentos eletrônicos, numa ampliação dos poderes dos órgãos de controle e na disseminação de mecanismos de vigilância (Souza, 2003, p. 164).

Mesmo considerando as particularidades nacionais, alguns estudos ${ }^{5}$ recentes apontam para dados que nos permitem afirmar que o Brasil também aderiu recentemente ao modelo de gestão penal neoliberal. Cada vez mais afeito a esse modelo de "estado mínimo", o Brasil adotou o que Lamounier e Souza (2006, p. 48) denominaram “democracia tutelada”. Segundo os autores, para orquestrar o desmanche estatal sem contestações políticas capazes de reverter o processo, o estado "testa até o limite o regime democrático, mas não o suprime em termos estritamente legais". Além disso, todos os problemas resultantes dessa desregulamentação, como a precarização das relações de trabalho, o desemprego e a dificuldade de acesso aos serviços essenciais, que podem levar ao aumento da criminalidade, não são solucionados, apenas a consequência se torna questão emergencial. Assim, observa-se o endurecimento das medidas repressivas "justificado pela retórica de 'defesa interna e externa' da nação", para silenciar os críticos.

5 No Brasil destacam-se os estudos do Instituto Carioca de Criminologia (ICC) que inaugurando, em certa medida, a perspectiva de análise exposta neste artigo, apontam para reflexões que avaliam a sociedade brasileira como uma "sociedade do controle" e o estado brasileiro como um exemplo particular de "estado penal". Pode-se dizer que Nilo Batista (2003a), criminólogo fundador desse instituto, inicia no Brasil esse viés científico, por meio da criminologia crítica. Vera Batista (2001) é outra pesquisadora que vinculada ao ICC estabelece reflexões pontuais sobre a segurança pública no Rio de Janeiro e sua configuração punitiva. Também analisando situações punitivas na cidade do Rio de Janeiro, Carlos Henrique Aguiar Serra (2011) argumenta que na sociedade brasileira há uma cultura do extermínio, que atualmente se imbrica no estado punitivo. Atrelando sua análise à reflexão de Agamben, Serra (2011, p. 110) também alega que esta conjuntura "coaduna-se na perpetuação da lógica do inimigo, na manutenção e legitimação de um estado de exceção, com fantasias e práticas de poderes absolutos, ilimitados por autoridades legais". Ainda sobre o tema, cuidadosa é a reflexão de André Moysés Gaio (2006, p. 118) ao destacar que embora a criminologia brasileira tenha se recusado "a abordar a criminalidade e a violência a partir de uma teoria geral da sociedade" é possível visualizar na sociedade brasileira "setores que defendem a aplicação de políticas cujo sentido se aproxima de uma abordagem da lei e da ordem". 
Quando começamos a observar as medidas de controle, sugeridas ou implementadas por diferentes setores do estado brasileiro, fica nítido a identidade de postura e objetivos. Embora o discurso político aponte várias iniciativas democráticas de controle, é a postura ostensiva e os objetivos repressivos que acabam se destacando na politica brasileira de controle social. Em outras palavras, todos os poderes insistem em afirmar que austeridade no trato do desvio é questão urgente e circunstancial. Judiciário, legislativo e executivo afinam seu discurso em um único tom de ordem a qualquer custo. Adiante alguns exemplos ilustram tal constatação.

Ainda que na prática a competência constitucional, ${ }^{6}$ associada à segurança pública, permaneça predominantemente com os estados da federação (por serem estes os responsáveis pela gestão das polícias civil e militar), o poder executivo brasileiro, primeiro a ser analisado, possui estrutura organizacional voltada para o controle social, como o Ministério da Justiça e a Secretaria Nacional de Segurança Pública; e cada vez mais toma para si a responsabilidade por unificar o discurso em torno do tema. É objetivo cada vez mais evidente do estado brasileiro a articulação entre as unidades federativas, "buscando aperfeiçoar o planejamento e troca de informações para uma atuação qualificada dos entes federados na área" (Freire, 2009, p. 52).

Desde o segundo governo de Fernando Henrique Cardoso que planos ${ }^{7}$ nacionais de segurança são elaborados com o intuito de transformar tal controle

6 Art. 144 da Constituição Federal de 1988:

"A segurança pública, dever do estado, direito e responsabilidade de todos, é exercida para a preservação da ordem pública e da incolumidade das pessoas e do patrimônio, através dos seguintes órgãos:

I - polícia federal;

II - polícia rodoviária federal;

III - polícia ferroviária federal;

IV - polícias civis;

$\mathrm{V}$ - polícias militares e corpos de bombeiros militares.

[...]

$\S 4^{\circ}$ - às polícias civis, dirigidas por delegados de polícia de carreira, incumbem, ressalvada a competência da União, as funções de polícia judiciária e a apuração de infrações penais, exceto as militares.

$\S 5^{\circ}$ - às polícias militares cabem a polícia ostensiva e a preservação da ordem pública; aos corpos de bombeiros militares, além das atribuições definidas em lei, incumbe a execução de atividades de defesa civil.

$\S 6^{\circ}-$ As polícias militares e corpos de bombeiros militares, forças auxiliares e reserva do Exército, subordinam-se, juntamente com as polícias civis, aos Governadores dos Estados, do Distrito Federal e dos Territórios".

7 O Plano Nacional de Segurança Pública (PNSP) criado em 2000, no governo de Fernando Henrique Cardoso, foi considerado a primeira política nacional e democrática de segurança focada no aperfeiçoamento do sistema de segurança pública através da integração de políticas de segurança, sociais e ações comunitárias. O PNSP "compreendia 124 ações distribuídas em 15 compromissos que estavam voltados para áreas diversas como o combate ao narcotráfico 
em uma questão de estado. Tais planos, porém, sempre acabaram figurando como conjuntos de metas, diretrizes distantes que apontavam para intenções políticas em detrimento de ações concretas no campo do controle. Há, inclusive, relevante distanciamento entre intensões democráticas e práticas altamente autoritárias revelando o caráter ideológico de tais documentos políticos.

Mecanismos essenciais não têm sido utilizados pelos diversos governos para possibilitar o pensar, o implementar, o implantar, o efetivar, com eficácia e eficiência, uma política de segurança pública como instrumento do estado e da sociedade. A promulgação de leis, decretos, portarias e resoluções, visando instrumentalizar o enfretamento da criminalidade e da violência, sem que haja articulação das ações de segurança pública no contexto social, acaba apresentando resultados inconsistentes e insatisfatórios (Carvalho; Silva, 2011, p. 62).

Recentemente, o governo brasileiro criou novamente um programa ${ }^{8}$ nacional de segurança visando transformá-lo em política de estado. Desenvolvido pelo Ministério da Justiça, o Programa Nacional de Segurança

e ao crime organizado; o desarmamento; a capacitação profissional; o reaparelhamento das polícias, a atualização da legislação sobre segurança pública, a redução da violência urbana e o aperfeiçoamento do sistema penitenciário. Uma novidade é que no plano, além dessas iniciativas na área específica de segurança, eram propostas diversas ações na esfera das políticas sociais. O plano, no entanto, não fixava os recursos nem as metas para ações. Ao mesmo tempo, não estavam estabelecidos quais seriam os mecanismos de gestão, acompanhamento e avaliação do plano" (Salla, 2003, p. 430). Já diretrizes políticas relacionadas à segurança pública implantadas pelo primeiro governo de Luis Inácio Lula da Silva surgiram em 2001, a partir da elaboração do Projeto de Segurança Pública para o Brasil pelo Instituto da Cidadania, organização não-governamental composta por Antonio Carlos Biscaia, Benedito Mariano, Roberto Aguiar e Luis Eduardo Soares. Tal projeto serviu de base para o programa de governo de Lula durante a disputa eleitoral em 2002. Segundo Soares (2007, p. 89), um de seus idealizadores, "as características elementares desse plano eram originais: tratava-se de um conjunto de propostas articuladas por tessitura sistêmica, visando a reforma das polícias, do sistema penitenciário e a implantação integrada de políticas preventivas, intersetoriais". Contudo destaca também Soares (2007, p. 91) que "a armadilha política, fruto da contradição entre o ciclo eleitoral e o tempo de maturação de políticas públicas reformistas, terminou levando o governo federal a aposentar, precocemente, seus compromissos ambiciosos na segurança pública: o Plano Nacional foi deslocado, progressivamente, do centro da agenda do Ministério da Justiça, e substituído, gradualmente, por ações da Polícia Federal, que passaram a emitir para a sociedade a mensagem de atividade competente e destemida, na contramão de nossa tradicional e corrosiva impunidade". Enfim, como atestam Carvalho e Silva (2011, p. 61), "tanto o PNSP do governo Fernando Henrique Cardoso, quanto a política de segurança pública empreendida pelo primeiro governo do presidente Luiz Inácio Lula da Silva não tiveram os resultados esperados".

8 O Pronasci foi criado através da Medida Provisória 384 e previa, até o fim de 2012, o investimento de $\mathrm{R} \$ 6,707$ bilhões em um conjunto de 94 ações que articulariam "programas de segurança pública com políticas sociais já desenvolvidas pelo governo federal, sem abrir mão das estratégias de controle e repressão qualificada à criminalidade”. 
Pública com Cidadania (Pronasci) se projetou como "uma iniciativa inédita no enfrentamento à criminalidade no país". Segundo o documento, o programa, ainda em vigor, pretende "articular políticas de segurança com ações sociais; priorizar a prevenção e buscar atingir as causas que levam à violência, sem abrir mão das estratégias de ordenamento social e segurança pública". Entre os principais eixos do Pronasci destacam-se a valorização dos profissionais de segurança pública; a reestruturação do sistema penitenciário; o combate à corrupção policial e o envolvimento da comunidade na prevenção da violência.

Ainda que textualmente pareça contrastar com o modelo punitivo que estamos aqui evidenciando, o programa na verdade mostra-se pouco representativo e essencialmente paradoxal, na medida em que, por exemplo, insiste em aliar a preocupação com a cidadania à ampliação do encarceramento. ${ }^{9}$ Nesse sentido, o Pronasci pouco alterou o espectro punitivo do controle social empregado. Mesmo com todo o investimento e parcerias, as medidas preventivas, de formação profissional e de capacitação de mulheres líderes das comunidades, por exemplo, ainda são inexpressivas. Ao contrário, ainda são recorrentes as imagens da força nacional de segurança apoiando-se no policiamento ostensivo, ou mesmo das forças armadas ocupando comunidades e implantado "choques de paz".

Operações gigantescas ${ }^{10}$ envolvendo polícias e forças armadas, equipadas com veículos blindados e helicópteros, ocupam o território povoado por miseráveis em um nítido exercício de guerrilha. É dessa forma perversa e truculenta que a segurança pública começa a se consolidar no país. É cada vez mais legitima tal atuação estatal que, apoiada pela cobertura sensacionalista da mídia, passa a representar o modelo eficiente de controle social. Com imenso aparato bélico polícias dominam ruas, invadem domicílios sem mandados, revistam moradores e fincam bandeiras simbólicas em pontos estratégicos do local. Toda a operação é marcada pela presença ostensiva da polícia que, como

9 O programa prevê a criação de mais de 40 mil vagas no sistema penitenciário do país para atender a públicos específicos (jovens entre 18 e 24 anos e mulheres preferencialmente). Para mais informações: <http://portal.mj.gov.br/pronasci/data/Pages/MJE24D0EE7ITEMIDAF 1131EAD238415B96108A0B8A0E7398PTBRNN.htm>.

${ }^{10}$ Exemplo emblemático desse modelo truculento de politica pública de segurança, a Rocinha, considerada a maior favela da América Latina, foi ocupada no dia treze de novembro de 2011 por cerca de 3.000 homens, munidos de sete helicópteros, dezoito blindados da Marinha e seis "caveirões" do Bope. Enquanto os blindados rasgavam as ruas, as aeronaves sobrevoaram a comunidade lançando panfletos com os dizeres "sua comunidade está sendo pacificada". No papel, havia e-mail e números de telefone para que os moradores denunciassem traficantes, esconderijos de armas e drogas. Mesmo com todo o arsenal bélico, a operação foi cinicamente denominada de "Choque de Paz". Para maiores informações sobre o tema confira Guimarães; Silveira; Paul (2012). 
um furacão, atua com a missão de destruir focos de atividades criminosas. Essa é a aproximação inicial que o estado promove com parcelas significativas da sociedade civil, historicamente abandonadas pelo poder público. O susto inicial é fundamental para que a mensagem seja compreendida: a questão social continua sendo um caso de polícia.

Esse modelo violento de gestão, propagandeado epicamente pela mídia, contribui para uma "sensação generalizada de permissividade a certos métodos e meios usados pela força armada" (Charleaux apud Ramos; Paiva, 2007, p. 57). Mais do que isso, uma atmosfera marcadamente autoritária começa permear ambientes democráticos transfigurando paulatinamente suas características essenciais. Territórios perigosos, inimigos em potencial e recursos bélicos parecem, cada vez mais, verdades absolutas a pautar as políticas de segurança pública.

Assim, é possível dizer que mesmo com o Pronasci o controle social em suas várias modalidades é ainda exercido mediante o paradigma punitivo, violento e seletivo. Nessa linha, nossos governos democráticos contemporâneos frequentemente adotaram uma posição punitiva que visa reafirmar a aptidão do estado em reprimir e controlar a criminalidade.

Quando o olhar se volta para o poder legislativo o que se observa não é muito diferente. Seguindo a mesma linha de defesa do recrudescimento punitivo o Congresso brasileiro vivencia atualmente uma inflação legislativa em matéria penal que apenas tem referendado as distorções e a seletividade do sistema. Essa foi exatamente a constatação de Frade (2007) ao analisar a recente produção legislativa no âmbito criminal. Segundo sua a pesquisa, dos 646 projetos de lei apresentados em apenas quatro anos no Congresso Nacional sobre criminalidade, "apenas 20 foram no sentido de relaxar algum tipo penal”. Ao contrário, “626 projetos destinavam-se a agravar penas, regimes e restrições” (Frade, 2007, p. 76). Não sem razão, apenas dois relacionavam-se com a delinquência de colarinho branco. É bom ressaltar que a "inclusão de algumas novas áreas dentro do denominado controle penal formal não foi compensada pela diminuição do rigor repressivo nas áreas tradicionalmente submetidas ao controle penal convencional" (Azevedo, 2005, p. 236).

Essa enxurrada de projetos de lei certamente culminou na elaboração do anteprojeto do novo código penal (PLS236/2012). Segundo o ministro do Superior Tribunal de Justiça, Gilson Dipp, que atualmente preside os trabalhos da comissão responsável pela elaboração do referido anteprojeto, houve mais de 2,5 mil manifestações de pessoas com sugestões feitas pelo site do Senado, mais de $90 \%$ delas pedindo o endurecimento de penas. Ainda segundo 
Dipp, a comissão não se rendeu a tais propostas populistas (Baliardo; Haidar, 2012).

Contudo, o projeto traz disposições altamente punitivas como o aumento máximo de cumprimento de pena privativa de liberdade de 30 para 40 anos (sobrevindo condenação por fato posterior ao inicio de cumprimento de pena); o aumento da pena para homicídio culposo, para os crimes contra a honra, para quem promover jogo de azar, explorar menores etc.; a flexibilização da progressão de regime que se dará com um sexto, um terço, metade e até três quintos da pena dependendo do crime, da reincidência etc.; e, principalmente, a criação de inúmeros tipos penais, vale dizer, novas condutas rotuladas como criminosas, como terrorismo, bullying, crimes eleitorais, cibernéticos, enriquecimento ilícito, uso de informações privilegiadas, além do aumento do rol de crimes hediondos entre outros.

Enfim, o remédio penal continua sendo utilizado pelas instâncias de poder político "como resposta para quase todos os tipos de conflitos e problemas sociais" (Azevedo, 2005, p. 236). A opção pelo caminho penal "se converte em resposta simbólica oferecida pelo estado em face de demandas de segurança e penalização da sociedade, expressas pela mídia, sem relação direta com a verificação de sua eficácia instrumental como meio de prevenção ao delito" (Azevedo, 2005, p. 236). Cada vez mais "o direito penal se converte em recurso público de gestão de condutas utilizado contingencialmente e não em instrumento subsidiário de proteção de interesses ou bens jurídicos" (Azevedo, 2005, p. 236).

Por fim, quando observamos a Justiça Penal, setor do estado em que tal postura punitiva é, sem dúvida, mais evidente, podemos visualizar com clareza que nossa principal resposta à criminalidade consiste em punição severa, traduzida, quase sempre, na ausência do respeito às garantias constitucionais e no recurso amplo ao encarceramento. Tal realidade adquire forma através da recorrência cada vez maior ao Direito Penal como solução em prima ratio de praticamente todos os conflitos que batem às portas do judiciário. Sua função, eminentemente simbólica, é atuar como mecanismo tranquilizador da opinião pública que, hegemonicamente, busca amparo e assistência ao invés de reconhecimento de seus direitos.

Nesse contexto, o novo credo do campo jurídico é o da equação penal que vê na pena severa a única medida capaz de controlar e, até mesmo, diminuir a criminalidade. Mais do que isso, “a pena já não interessa tanto como inflição de sofrimento ou mesmo fórmula desastrada de solução de conflitos: a pena interessa como recurso epistemológico, como instrumento de compreensão do mundo" (Batista, 2003b, p. 8). 
Em outras palavras, em tempos liberais como o atual, o que caracteriza a atuação penal é a noção de emergência, entendida como um momento excepcional a exigir "uma resposta pronta e imediata, que deve durar enquanto o estado emergencial perdure" (Beck, 2004, p. 95). Aqui não cabe qualquer objetivo educador, reformador ou disciplinador, apenas o isolamento e a exclusão.

Cada vez mais a criminologia contemporânea sustenta a ineficácia da reabilitação penal abrindo caminho para a legitimação da punição meramente retributiva. Esse novo paradigma altera a imagem das classes populares carentes de políticas sociais e as configura como inaptas, quando não simples parasitas do estado (Salla; Gauto; Alvarez, 2006, p. 334). Verifica-se, portanto, o abandono do discurso criminológico ressocializador permitindo, cada vez mais, a consideração da punição como simples "instrumento de encerramento de uma população considerada tanto desviante e perigosa como supérflua, no plano econômico". Tal punição representa tão somente um mecanismo útil para "segregar uma categoria indesejável, percebida como provocadora de uma dupla ameaça, inseparavelmente física e moral" (Wacquant, 2001, p. 98).

Uma das características dos novos sistemas penais do empreendimento neoliberal consiste numa radical transformação nas finalidades da privação de liberdade, que passam daquilo que Zaffaroni chamou de 'ideologias re' (reinserção social, recuperação laborativa, redisciplinamento etc.) a uma assumida técnica de neutralização do condenado (Batista, 2000, p. 107) (sic).

Como assevera Guindani (2005, p. 8) "o conceito de reabilitação foi totalmente desmistificado a partir dos anos 80 e as teorias que assumiam a punição como forma de tratamento e ressocialização foram desmascaradas [...] diante de argumentos ambíguos sobre a execução penal". Cada vez mais impregnada pelos valores neoliberais, que naturalizam a exclusão à semelhança do darwinismo social, a sociedade contemporânea condena sumariamente o infrator, desejando imediatamente seu descarte. Hoje em dia os programas de reabilitação que ainda existem no país "não mais reivindicam o status de expressão máxima da ideologia do sistema, nem mesmo a posição de objetivo primordial de qualquer medida penal". As possibilidades de reabilitação das medidas penais, quando propagadas, estão na maioria das vezes subordinadas a objetivos penais mais explícitos como a "retribuição, neutralização e o gerenciamento de riscos" (Garland, 2008, p. 51). 
Evidência marcante dessa constatação, portanto, é a enorme expansão do sistema penitenciário verificável a partir da reabertura política de 1988. O Brasil, ao aumentar vertiginosamente nos últimos anos seu número de encarcerados, ultrapassou, no ano de 2012, a marca dos 549.000 presos. Segundo dados ${ }^{11}$ do Departamento Penitenciário Nacional (Depen), a população carcerária, que em 1988 era de 88.041 presos, o que representava taxa de encarceramento de 65,2 por cem mil habitantes, atingiu, em julho de 2012 espantosos 549.577 presos, elevando a taxa de encarceramento para 288,14 por cem mil habitantes. $\mathrm{O}$ aumento ${ }^{12}$ foi da ordem de $524 \%$ o que representa 461.536 presos a mais no sistema. O sistema penitenciário brasileiro, por sua vez, ocupa, de acordo com dados do Departamento Penitenciário Nacional (Depen), 1420 estabelecimentos com um total de 309.074 vagas (homens: 287.150 e mulheres: 21.924), e, portanto, déficit de mais de 240.000 vagas.

Tal aumento da população prisional, sob esta perspectiva, não é exclusividade nacional, ${ }^{13}$ dada à característica neoliberal de sua constatação. Wacquant (2001), ao analisar o inchaço das penitenciárias norteamericanas, comentou que "se fosse uma cidade, o sistema penitenciário americano seria a quarta metrópole do país". Esse encarceramento em massa reflete, para Bauman (1999) e Wacquant (2001), uma estrutura de dominação contemporânea que mascara uma exclusão capitalista ainda mais perversa, vale dizer, o isolamento e a neutralização dos miseráveis em praticamente todo o globo. Como bem assevera Christie (2002, p. 93), "são as decisões político-culturais que determinam a estatística carcerária e não o nível ou evolução da criminalidade". O maior encarceramento não tem, portanto, relação direta com o aumento das práticas criminosas, mas

${ }^{11}$ Para mais informações sobre o perfil do cárcere brasileiro consulte o Relatório estatistico de 2012 produzido pelo Depen e disponível na página virtual do Ministério da Justiça: http://portal.mj.gov. br/data/Pages/MJD574E9CEITEMIDC37B2AE94C6840068B1624D28407509CPTBRNN. htm. Acesso em: 11 dez. 2012.

${ }^{12}$ Em resposta a esse aumento, dados da Secretaria Nacional de Segurança Pública atestam que o total de gastos realizados pelos governos estaduais em segurança pública subiu de R \$ 24 bilhões para R \$ 33,5 bilhões, de 2005 para 2008. Em relação aos gastos por habitante, este crescimento representou um aumento de $36 \%$, passando de $\mathrm{R} \$ 130,52$ para $\mathrm{R} \$ 176,95$ por habitante. Para mais informações sobre os investimentos nacionais em segurança pública consulte o Relatório elaborado pela Coordenação Geral de Pesquisa / Senasp / MJ disponível na página virtual da Secretaria Nacional de Segurança Pública: http://portal.mj.gov.br/data/ Pages/MJCF2BAE97ITEMID6CB4BC7A517B4668A5F12EFC98FFCEFEPTBRIE.htm. Acesso em: 24 jul. 2012.

${ }_{13}$ Ao descrever a geografia penal contemporânea, mesmo com alguns números imprecisos, Christie (2002) diagnosticou o aumento da população prisional em praticamente todos os continentes. Essa foi também a constatação feita pelo International Centre for Prisions Studies, do King's College London (Walmsley, 2009). Segundo pesquisa realizada pelo instituto, existia no mundo, em dezembro de 2008, cerca de 9,8 milhões de pessoas presas. 
sim com o aumento dos miseráveis, totalmente excluídos do universo do trabalho.

Os cuidados com o "estado ordeiro", outrora uma tarefa complexa e intricada que refletia as variadas ambições e a ampla e multifacetada soberania do estado, tendem a reduzir-se consequentemente à tarefa de combate ao crime. Nessa tarefa, porém, um papel cada vez maior, com efeito o papel central, é atribuído à política de confinamento. A essencialidade do combate ao crime não explica por si só o boom penitenciário; afinal, há também outras maneiras de combater as reais ou supostas ameaças à segurança pessoal dos cidadãos. Além disso, colocar mais gente na prisão, e por mais tempo, até aqui não se mostrou a melhor maneira. É de supor, portanto, que outros fatores levam à escolha da prisão como prova mais convincente de que de fato "algo foi feito", de que as palavras correspondem à ação. Colocar a prisão como estratégia crucial na luta pela segurança dos cidadãos significa atacar a questão numa linguagem contemporânea, usar uma linguagem que é prontamente compreendida e invocar uma experiência comumente conhecida (Bauman, 1999, p. 129).

Encarcerando cada vez mais e por mais tempo as classes populares, via de regra, por pequenos delitos contra o patrimônio ou por condutas ligadas ao pequeno comércio de entorpecentes, desvia-se, de forma estratégica, a atenção dos inúmeros crimes contra a ordem econômica e financeira praticados pela elite política. Tal realidade denota claramente que a pobreza não está associada diretamente à criminalidade, mas sim "reproduz a vitimização ${ }^{14}$ e a criminalização dos pobres, o desrespeito aos seus direitos e a sua falta de acesso à justiça" (Caldeira, 2000, p. 134). E é assim que caminha a Justiça Penal, vale dizer, para a consolidação do "estado punitivo", voltado para a defesa da lei e da ordem liberal, materializado no encarceramento em massa e ilegal de membros das classes populares. Nesse enredo socioeconômico e cultural cada vez mais evidente no Brasil a própria Justiça é também retrato da adesão às premissas liberais refletidas no excessivo, desumano e desigual tratamento penal.

\footnotetext{
${ }^{14}$ Uma das expressões mais dramáticas dessa realidade é representada pelos altos índices de homicídios que vitimizam predominantemente as populações mais carentes. De acordo com a Organização Mundial da Saúde, em seu último relatório sobre violência, a América Latina possui o pior registro de índices de homicídio no planeta. "O Brasil, um dos países mais violentos da região, acumulou mais de 800.000 mortes por homicídio doloso nas últimas duas décadas. Mais pessoas se tornam vítimas de homicídio a cada ano no Brasil do que na Guerra do Iraque. É importante dizer que uma ampla maioria dos mortos é economicamente desfavorecida, pouco instruída, jovem, masculina, negra e residente na periferia social brasileira" (Vieira, 2007, p. 43).
} 
Conforme já salientamos, a história do Brasil é uma combinação permanente e alternada de paternalismo e repressão (Fiori, 1995). No atual contexto liberal a repressão violenta volta a ser protagonista e ganha novos contornos, mas o alvo continua sendo o refugo social que, dada nossa desigualdade perversa, sempre possuímos. Enfim, mantendo tal política o estado brasileiro atua de forma ambígua, propagando incessantemente sua democratização, mas cumprindo a lei de maneira tortuosa, agindo, assim, de forma autoritária e seletiva.

\section{Referências}

AGAMBEN, Giorgio. Estado de exceção. São Paulo: Boitempo Editorial, 2004.

ANDRADE, Vera Regina Pereira de. A colonização da justiça pela justiça penal: potencialidades e limites do judiciário na era da globalização neoliberal. Revista de Estudos Criminais, Florianópolis, v. 9, p. 41-48, 2009.

ARGËLLO, Katie. Do estado social ao estado penal: invertendo o discurso da ordem. I Congresso de Criminologia, Londrina, novembro, 2005.

AZEVEDO, Rodrigo Ghiringhelli. Criminalidade e Justiça Penal na América Latina. Sociologias, Porto Alegre, v. 7, n. 13, p. 212-241, jan.-jun 2005.

BALIARDO, Rafael; HAIDAR, Rodrigo. Aumento de pena não é garantia de punição. Consultor Jurídico. Edição do dia 06/05/2012. Disponível em: <http://www.conjur. com.br/2012-mai-06/entrevista-gilson-dipp-presidente-comissao-reforma-codigopenal>.

BAUMAN, Zygmunt. Modernidade líquida. Rio de Janeiro: Jorge Zahar, 2001. . Globalização: as consequências humanas. Rio de Janeiro: Jorge Zahar,1999.

BATISTA, Nilo. Novas tendências do direito penal. Palestra proferida pelo Centro de Estudos Judiciários do Conselho da Justiça Federal (CJF) e realizada no auditório do Superior Tribunal de Justiça (STJ), no Distrito Federal, no dia 8 de maio, 2003a.

. Mídia e Sistema Penal no capitalismo tardio. Revista Brasileira de Ciências Criminais, São Paulo, v. 11, n. 42 (esp.), jan.-mar. 2003 b.

Prezada senhora Viégas: o anteprojeto de reforma no sistema de penas. Discursos sediciosos - Crime, direito e sociedade, Rio de Janeiro, v. 5, n. 9 e 10, p. 107, 2000.

BATISTA, Vera Malaguti. Autoritarismo e controle social no Brasil - Memória e medo. Revista Sem Terra, São Paulo, n. 10, p. 80-84, 2001.

BECK, Francis Rafael. Perspectivas de controle ao crime organizado e críticas à flexibilização de garantias. São Paulo: IBCCRIM, 2004.

CALDEIRA, Teresa Pires do Rio. Cidade de muros: crime, segregação e cidadania em São Paulo. São Paulo: Edusp e Ed. 34, 2000.

CARVALHO, Vilobaldo Adelídio de; FÁTIMA E SILVA, Maria do Rosário de. Política de segurança pública no Brasil: avanços, limites e desafios. Revista Katálysis, Florianópolis, v. 14, n. 1, p. 59-67, jan.-jun., 2011. 
CHRISTIE, Nils. Elementos de geografia penal. Discursos sediciosos - Crime, direito e sociedade, Rio de Janeiro, ano 7, n. 11, 2002.

FIORI, José Luís. Em busca do dissenso perdido: ensaios críticos sobre a festejada crise do estado. Rio de Janeiro: Insight, 1995.

FRADE, Laura. O que o Congresso Nacional brasileiro pensa sobre a criminalidade. Tese (Doutorado) - Departamento de Sociologia, Universidade de Brasília (UnB), 2007.

FREIRE. Moema Dutra. Paradigmas de segurança no Brasil: da ditadura aos nossos dias. Aurora, Marília, v. 3, n. 5, dez. 2009.

GAIO, André. Moyses. Crime e controle social no Brasil contemporâneo. Teoria e Cultura, UFJF, v. 1, n. 2, p. 111-127, 2006.

GARLAND, David. A cultura do controle: crime e ordem social na sociedade contemporânea. Rio de Janeiro: Revan, 2008.

As contradições da 'sociedade punitiva': o caso britânico. Revista de Sociologia e Política, Curitiba, n. 13, p. 59-80, nov. 1999.

GIDDENS, Antony; BECK, Ulrich; LASCH, Scoth. Modernização reflexiva: política, tradição e estética na ordem social moderna. São Paulo: Ed. Unesp, 1995.

GUIMARÃES, Isabel Padilha; SILVEIRA, Ada Cristina Machado da; PAUL, Dairan Mathias, A guerra que não aconteceu: análise da ocupação na Rocinha pela cobertura do G1 e do Globo News. Trabalho apresentado no $13^{\circ}$ Congresso de Ciências da Comunicação na Região Sul, Chapecó, Santa Catarina, realizado entre os dias 31 de maio e 2 de junho de 2012.

GUINDANI, Miriam. Sistemas de política criminal no Brasil: retórica garantista, intervenções simbólicas e controle social punitivo. Caderno Cedes, Rio de Janeiro, n. 2, 2005.

HARVEY, David. Condição pós-moderna. 15. ed. São Paulo: Edições Loyola, 2010.

JAKOBS, Günter; CANCIO MELIÁ, Manuel. Derecho penal del enemigo. Madrid: Civitas, 2003.

JAMESON, Fredric. Pós-modernidade e sociedade de consumo. Novos Estudos Cebrap, São Paulo, n. 12, p. 16-26, jun. 1985.

LAMOUNIER, Bolívar; SOUZA, Amaury. O futuro da democracia: cenários políticoinstitucionais até 2022. Revista Estudos Avançados, São Paulo, v. 20, n. 56, p. 44-60, 2006.

NEDER, Gizlene. Absolutismo e punição. Discursos sediciosos - Crime, direito e sociedade. Rio de Janeiro: Relume Dumará, v. 1, n. 1, p. 191-206, 1996.

OLIVEIRA, Francisco. Memórias do despotismo. Revista Estudos Avançados, São Paulo, v. 14, n. 40, p. 59-63, set.-dez. 2000.

RAMOS, Silvia; PAIVA, Anabela. Mídia e violência: novas tendências na cobertura de criminalidade e segurança no Brasil. Rio de Janeiro: Iuperj, 2007.

SALLA, Fernando. Os impasses da democracia brasileira: o balanço de uma década de políticas para as prisões no Brasil. Revista Lusotopie, Paris, v. 10, p. 419-435, 2003. 
SALLA Fernando; GAUTO Maitê; ALVAREZ Marcos César. A contribuição de David Garland: a sociologia da punição. Tempo Social, São Paulo, v. 18, n. 1, p. 329-350, jun. 2006.

SERRA, Carlos; AGUIAR, Henrique. Violência e estado punitivo no Brasil contemporâneo.Prim@Facie, v. 10, p.108-118, 2011.

SOARES, Luiz Eduardo. A política nacional de Segurança Pública: histórico, dilemas e perspectivas. Estudos Avançados, São Paulo, v. 21, n. 61, p. 77-97, dez. 2007.

SOUZA, Luís Antônio Francisco. Obsessão securitária e a cultura do controle. Revista de Sociologia e Política, São Paulo, n. 20, p. 161-165, jun. 2003.

VIEIRA, Oscar Vilhena. A desigualdade e a subversão do estado de direito. Sur Revista Internacional de Direitos Humanos, São Paulo, v. 4, n. 6, 2007.

WACQUANT, Loïc. Punir os pobres: a nova gestão da miséria nos EUA. Rio de Janeiro: Freitas Bastos, 2007. . As prisões da miséria. Rio de Janeiro: Jorge Zahar Editor, 2001.

. (Entrevista) A criminalização da pobreza. Mais Humana, dez. 1999. Disponível em: <www.maishumana.com.br/loic1.htm>. Acesso em: 10 ago. 2012.

WALMSLEY, Roy. World prison population list. 8. ed. London: Centre for Prison Studies, King's College London, Jan. 2009.

Data de recebimento: 10/02/2013.

Data de aprovação: 30/03/2013.

Autora correspondente:

Débora Pastana

Avenida Lazara Alves Ferreira, 80, ap. 701-B - Santa Mônica

38408-092 Uberlândia, MG 